\title{
Uptake and emission of VOCs near ground level below a mixed forest at Borden, Ontario
}

\author{
M. Gordon ${ }^{1}$, A. Vlasenko ${ }^{1,}{ }^{*}$, R. M. Staebler ${ }^{1}$, C. Stroud ${ }^{1}$, P. A. Makar ${ }^{1}$, J. Liggio ${ }^{1}$, S.-M. Li ${ }^{1}$, and S. Brown ${ }^{2}$ \\ ${ }^{1}$ Atmospheric Science and Technology Directorate, Science and Technology Branch, Environment Canada, Toronto, Canada \\ ${ }^{2}$ Agriculture and Forest Meteorology, Guelph University, Guelph, Canada \\ *now at: Airzone One Ltd., Mississauga, ON, Canada
}

Correspondence to: R. M. Staebler (ralf.staebler@ec.gc.ca)

Received: 30 January 2014 - Published in Atmos. Chem. Phys. Discuss.: 20 February 2014

Revised: 19 June 2014 - Accepted: 26 June 2014 - Published: 5 September 2014

\begin{abstract}
Understanding of the atmosphere/forest canopy exchange of volatile organic compounds (VOCs) requires insight into the deposition, emission, and chemical reactions of VOCs below the canopy. Between 18 July and 9 August 2009, VOCs were measured with proton-transfer-reaction mass spectrometry (PTR-MS) at six heights between 1 and $6 \mathrm{~m}$ beneath a $23 \mathrm{~m}$ high mixed-forest canopy. Measured VOCs included methanol, isoprene, acetone, methacrolein and methyl vinyl ketone (MACR + MVK), monoterpenes, and sesquiterpenes. There are pronounced differences in the behaviour of isoprene and its by-products and that of the terpenes. Non-terpene mixing ratios increase with height, suggesting predominantly downward fluxes. In contrast, the terpene mixing ratios decrease with height, suggesting upward fluxes. A 1-D canopy model was used to compare results to measurements with and without surface deposition of isoprene and MACR + MVK and emissions of monoterpenes and sesquiterpenes. Results suggest deposition velocities of $2.7 \mathrm{~mm} \mathrm{~s}^{-1}$ for isoprene and $1.2 \mathrm{~mm} \mathrm{~s}^{-1}$ for MACR + MVK and daytime surface emission rates of $63 \mu \mathrm{g} \mathrm{m}^{-2} \mathrm{~h}^{-1}$ for monoterpenes. The modelled isoprene surface deposition is approximately $2 \%$ of the canopy-top isoprene emissions and the modelled emissions of monoterpenes comprise approximately 15 to $27 \%$ of the canopy-top monoterpene emissions to the atmosphere. These results suggest that surface monoterpene emissions are significant for forest canopy/atmosphere exchange for this mixed-forest location and surface uptake is relatively small for all the species measured in this study.
\end{abstract}

\section{Introduction}

Biogenic volatile organic compounds (BVOCs) can play a significant role in atmospheric chemistry (Schade et al., 2010) and forests are a significant source of BVOC emissions (Lappalainen et al., 2009). The emission of BVOCs is the largest terrestrial source of reactive carbon in the atmosphere and isoprene is the largest contributor (Guenther et al., 1995). BVOCs are involved in the formation and growth of atmospheric aerosol particles (Tunved et al., 2006). Holzinger et al. (2005) found a large number of higher molecular weight compounds (>100 amu) in the air within and above a ponderosa pine plantation. Most compounds are from reactions between ozone and terpenoids emitted from the forest (Calogirou et al., 1999) while some are from the reaction of ozone with leaf surfaces (Fruekilde et al., 1998; Wildt et al., 2003). Methanol is produced in plants and is attributed to plant cell wall growth and repair (Kreuzwieser et al., 2000). Isoprene, monoterpene, and methanol emissions are controlled by air temperature (Tingey et al., 1980) and light intensity (Guenther et al., 1991; Folkers et al, 2008). However, direct correlations are difficult to measure, as plants acclimate to the environment following cues from previous hours, days, or even seasons (Oquist and Huner, 2003, Mäkelä et al., 2004).

The loss of BVOCs to reactions within the canopy is a poorly understood process. Makar et al. (1999) found a $40 \%$ loss of isoprene due to in-canopy chemistry using a 1-D canopy model, while the isoprene loss modelled by Karl and Guenther (2005) was between 2 and 5\%. It is unknown how production and loss of volatile organic compounds (VOCs) are connected to reactions at the forest surface. Leaf litter and 
forage have been identified as potentially significant sources of VOCs in the atmosphere (Kirstine et al., 1998; Warneke et al., 1999; de Gouw et al., 1999; Shade et al., 1999; Leff and Fierer, 2008). Leaf litter may be a strong source of methanol, possibly accounting for $40 \times 10^{12}$ g year $^{-1}$ of global emissions (Warneke et al., 1999). Leff and Fierer (2008) found that non-methane VOC production rates were higher in leaf litter samples than in soil and the rates were correlated with microbial biomass. Uptake of methane in soils is generally microbially mediated (Schade et al., 1999) and recent research suggests this may also be the case for methanol (Stacheter et al., 2013). Compounds such as methanol, acetaldehyde, and acetone can also be released from decaying plant material (Warneke et al., 1999).

In a recent study by Stroud et al. (2005), a 1-D model was compared to VOC measurements made at a pine plantation in order to determine escape efficiencies for terpenoid emissions. The model output was compared to sub-canopy measurements of isoprene, pinene, and methacrolein and methyl vinyl ketone (MACR + MVK). To improve model accuracy near the forest floor, surface deposition of isoprene and MACR + MVK (both $2 \mathrm{~mm} \mathrm{~s}^{-1}$ ) and emission of $\alpha, \beta$ pinene $\left(69 \mu \mathrm{g} \mathrm{m}^{-2} \mathrm{~h}^{-1}\right)$ were added to the model. Although the surface deposition of isoprene and MACR + MVK is a negligibly small fraction of the canopy-top fluxes, the surface emission of $\alpha, \beta$-pinene, which is attributed to decaying pine needles, is $10 \%$ of the canopy-top flux.

Measurements to verify these deposition and emission rates are limited. In the same pine forest of the Stroud et al. (2005) study, Karl et al. (2005) used an inverseLagrangian model with VOC profile measurements to demonstrate a surface uptake of methanol, acetone, and $\mathrm{MVK}+\mathrm{MARC}$, and the emission of $\mathrm{C} 3 / \mathrm{C} 4$ carbonyls. These results verified the Stroud et al. (2005) approximations. A previous report of the same study (Karl and Guenther, 2005) also showed a surface uptake of isoprene and emission of monoterpenes. In a tropical rainforest, Karl et al. (2004) used an inverse-Lagrangian model with VOC profile measurements to demonstrate a surface uptake of methanol, acetone, and isoprene. Aaltonen et al. (2011) used sample chambers in a boreal pine forest and measured surface emissions of isoprene, monoterpenes, and sesquiterpenes $(0.05,5.04$, and $0.04 \mu \mathrm{g} \mathrm{m}^{-2} \mathrm{~h}^{-1}$, respectively). Hence, there is a large amount of variation in both the direction and magnitude of surface flux measurements.

The goal of this study was to quantify the uptake and emissions of VOCs by a surface beneath a mixed-deciduous forest canopy. We deployed a proton-transfer-reaction time-offlight mass spectrometer (PTR-ToF-MS) at the Borden Forest Research Station to measure VOC profiles near the forest floor in July and August 2009. Based on these measurements, the 1-D canopy model of Makar et al. (1999) and Stroud et al. (2005) was modified to include deposition and emissions of VOCs, allowing for the investigation of the relative importance of VOC uptake and emissions at this sub-canopy surface.

\section{Methods}

\subsection{Site description}

This study took place at the Borden Forest Research Station $\left(44^{\circ} 19^{\prime} \mathrm{N}, 79^{\circ} 56^{\prime} \mathrm{W}\right)$ in Ontario, Canada. The study was part of a larger study investigating aerosol fluxes (Gordon et al., 2011), isotopes (Santos et al., 2012), and sub-canopy transport (Brown et al., 2013). A 2006 stem count (Teklemariam et al., 2009) gave a forest composition of $52 \%$ red maple (Acer rubrum L.), $14 \%$ eastern white pine (Pinus strobus L.), $8 \%$ large-tooth aspen (Populus grandidentata Michx), $7 \%$ white ash (Fraxinus americana L.), and $6 \%$ American beech (Fagus grandifolia), with the remainder composed of a mixture of aspen, ash, cherry, pine, elm, and maple. The forest is regrowth on abandoned farm land, with an age of approximately 100 years (Lee et al., 1999). During the 2009 summer, the average canopy height was approximately $23 \mathrm{~m}$ with an understorey height of approximately $9 \mathrm{~m}$. The forest soil is loamy sand (Barr et al., 2002) composed of $91 \%$ sand, $6 \%$ silt, and $3 \%$ clay (Chang, 2011). The surrounding area is generally flat within a radius of about $4 \mathrm{~km}$. The available forest fetch is about $4.3 \mathrm{~km}$ to the south, and $3 \mathrm{~km}$ to the $S S W$. Outside of this range was predominantly grass and cropland, with the town of Angus, Ontario less than $4 \mathrm{~km}$ to the ENE and the Canadian Forces Base Borden $5 \mathrm{~km}$ to the SE.

\subsection{Instrumentation}

The Borden Forest Research Station includes a $44 \mathrm{~m}$ tower, which supports an array of instruments for routine measurements of temperature, wind speed, humidity, and fluxes of energy, water vapour, and $\mathrm{CO}_{2}$. Details of the measurement setup can be found in Lee et al. (1999), Staebler et al. (2000), Barr et al. (2002), and Teklemariam et al. (2009). Incoming shortwave radiation (SW) was measured (CNR1, Kipp \& Zonen) above the canopy, and photo-synthetically active radiation (PAR) was measured (LI-191, Licor Inc.) at the forest floor. Temperature was measured at 12 heights between 1.7 and $41.5 \mathrm{~m}$. A 3-D sonic anemometer (K-Type, Applied Technologies Inc.) was mounted on the tower at $33 \mathrm{~m}$ and measured turbulence at $10 \mathrm{~Hz} . \mathrm{O}_{3}$ was measured (49i, Thermo Scientific Inc.) at six heights between 1 and $41.5 \mathrm{~m}$. NO was also measured ( $42 \mathrm{~s}$, Thermo Scientific Inc.) between 16 July and 12 August 2006 at the same 6 heights as $\mathrm{O}_{3}$; however, $\mathrm{NO}$ measurements at the tower were not available during the 2009 study. To estimate the NO values during the 2009 study, measurements at a station $15 \mathrm{~km}$ south of the Borden forest (Egbert, ON) were used. The Egbert station is an open area above the surrounding canopy. During the 2006 measurements, the median hourly values of $\mathrm{NO}$ at Borden (at the $41.5 \mathrm{~m}$ height $)$ and at Egbert correlated well $\left(r^{2}=0.68\right)$ 
with an average of $0.26 \mathrm{ppb}$ at Egbert and $0.27 \mathrm{ppb}$ at Borden. This suggests that the Egbert NO measurements are a suitable proxy for above-canopy Borden NO values. To estimate the sub-canopy NO profiles, average profiles were generated from the 27 days of 2006 Borden tower measurements for each hour of the day. These hourly profile shapes were normalized with the $41.5 \mathrm{~m}$ height value. The normalized profile shapes were then scaled to the above-canopy values estimated from the 2009 Egbert station measurements. Sensitivity of the model to NO approximation is discussed in Sect. 4.2.

A proton-transfer-reaction time-of-flight mass spectrometer (PTR-ToF-MS, Ionicon Inc.), installed at ground level, was operational from 18 July to 9 August 2009. The PTRToF-MS sampled from six levels (heights of 1, 2, 3, 4, 5, and $6 \mathrm{~m})$ on a $6 \mathrm{~m}$ tower. Samples were drawn though $12 \mathrm{~m}$ of $6.35 \mathrm{~mm}(0.25 \mathrm{inch})$ outside diameter Teflon tubing at each level. The residence time was measured at $\sim 2 \mathrm{~s}$ by introducing benzene pulses to each line and timing the response. An automated valve system switched between each line once per minute. Each 1 minute average was background subtracted and normalized by the $m / z 21$ reagent ion signal and subsequently converted to mixing ratio using gravimetrically prepared calibration standards. Due to a lack of calibration standards, the sesquiterpene concentrations were estimated using the monoterpene standard. Since the sesquiterpene calibration ratio is known to be linear (Kim et al., 2009), the mixing ratios are presented as relative values without units. Uncertainty in all the PTR-ToF-MS measurements is estimated at $20 \%$. The 1 min concentration measurements at the six levels were averaged in $30 \mathrm{~min}$ intervals. Due to instrument malfunction, $6.5 \%$ of the $30 \mathrm{~min}$ profiles from 22 days could not be used. To ensure adequate fetch and horizontal homogeneity, measurements were filtered to use only wind direction in the range $20^{\circ}$ to $285^{\circ}$ following Teklemariam et al. (2009) and Froelich (personal communication, 2013). This resulted in the removal of $17.8 \%$ of the remaining data.

\subsection{Canopy modelling}

The canopy model is described in detail in Makar et al. (1999) and Stroud et al. (2005). It is a 1-D model which solves the equation,

$$
\frac{\partial C_{i, j}}{\mathrm{~d} t}=E_{i, j}+f_{i, j}+\frac{\partial}{\mathrm{d} z}\left(K\left(z_{j}\right) \frac{\partial C_{i, j}}{\mathrm{~d} z}\right),
$$

where $C_{i, j}, E_{i, j}$, and $f_{i, j}$ are the concentration, emissions rate, and rate of change due to chemical reactions, respectively, of the $i$ th chemical species in the $j$ th model layer, $K\left(z_{j}\right)$ is the eddy diffusivity, $t$ is time, and $z$ is height. The model domain is $1001 \mathrm{~m}$ with a $1 \mathrm{~m}$ vertical resolution and a 1 min time resolution. Environmental inputs to the model are at a $30 \mathrm{~min}$ time resolution and include temperature $(T)$, relative humidity $(\mathrm{RH})$, pressure, $\mathrm{PAR}$, cloud fraction, $\mathrm{O}_{3}$ and NO concentrations, and vertical wind variance $\left(\sigma_{\mathrm{w}}\right)$. Median

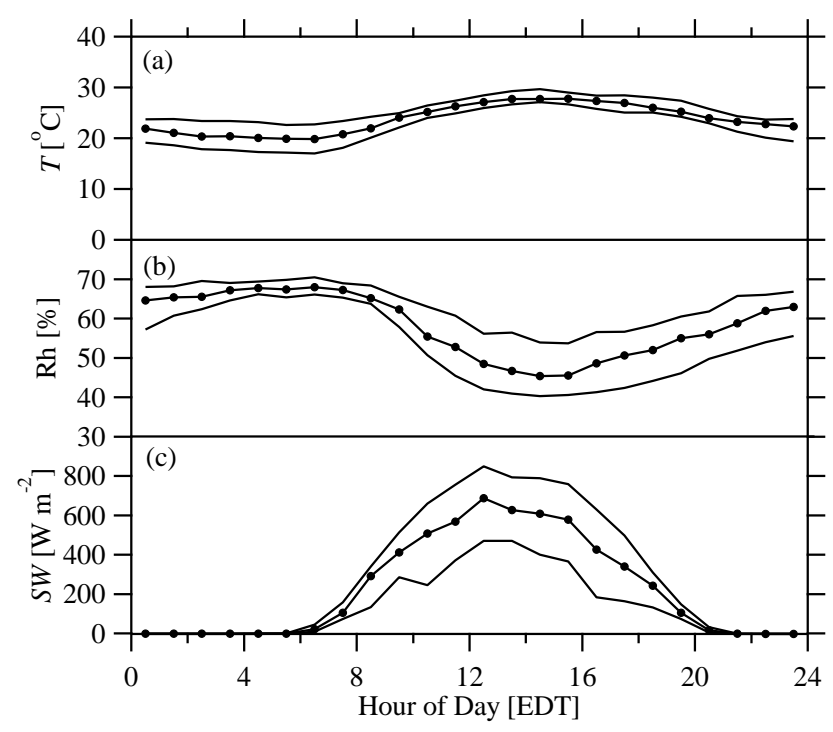

Figure 1. Hourly median and quartiles of (a) temperature, $T$, (b) relative humidity, $\mathrm{RH}$, and (c) incoming solar radiation, $\mathrm{SW}$, all at a height of $33 \mathrm{~m}$, for the 22 days of the study.

diurnal variations of temperature, relative humidity, and incoming solar radiation are shown in Fig. 1. Leaf area index (LAI) profiles were updated for the Borden forest based on 2009 measurements at a $2 \mathrm{~m}$ resolution. Eddy diffusivity $(K)$ above the canopy was output from the global environmental multiscale (GEM) Model (Côté et al., 1998) for the Borden location concurrent with the time period of the study.

The atmospheric transport within the canopy model is based on a modified $K$-theory of vertical turbulent diffusion from Raupach (1989),

$$
\frac{\partial C}{\mathrm{~d} t}=-\frac{\partial}{\mathrm{d} z}\left(R\left(\tau / T_{\mathrm{L}}\right) K \frac{\partial C}{\mathrm{~d} z}\right),
$$

where the eddy diffusivity $(K)$ is modified by the factor $R$, which accounts for canopy effects on turbulence (so-called "near-field" effects). The variable $R$ is dependent on the ratio of $\tau / T_{\mathrm{L}}$ as

$R=\frac{\left[1-\exp \left(-\tau / T_{\mathrm{L}}\right)\right]\left(\tau / T_{\mathrm{L}}-1\right)^{3 / 2}}{\left[\tau / T_{\mathrm{L}}-1+\exp \left(-\tau / T_{\mathrm{L}}\right)\right]^{3 / 2}}, \quad \tau / T_{\mathrm{L}}>1$,

where $\tau$ is a transport lifetime and $T_{\mathrm{L}}$ is the Lagrangian timescale. Makar et al. (1999) found the modelled isoprene measurements above the canopy agreed well with measurement at the Borden forest location using a transport lifetime of $\tau=1.17 T_{\mathrm{L}}$, while Stroud et al. (2005) found that a value of $\tau=4.0 T_{\mathrm{L}}$ improved results at the Duke Forest location. The model version used in the Stroud et al. (2005) study was modified to use a diffusion scheme which allowed for the inclusion of deposition and emissions at the surface. Stroud et al. (2005) hypothesized that the difference in transport lifetime could be due to either the change in the diffusion scheme or a difference in the canopy structure between 


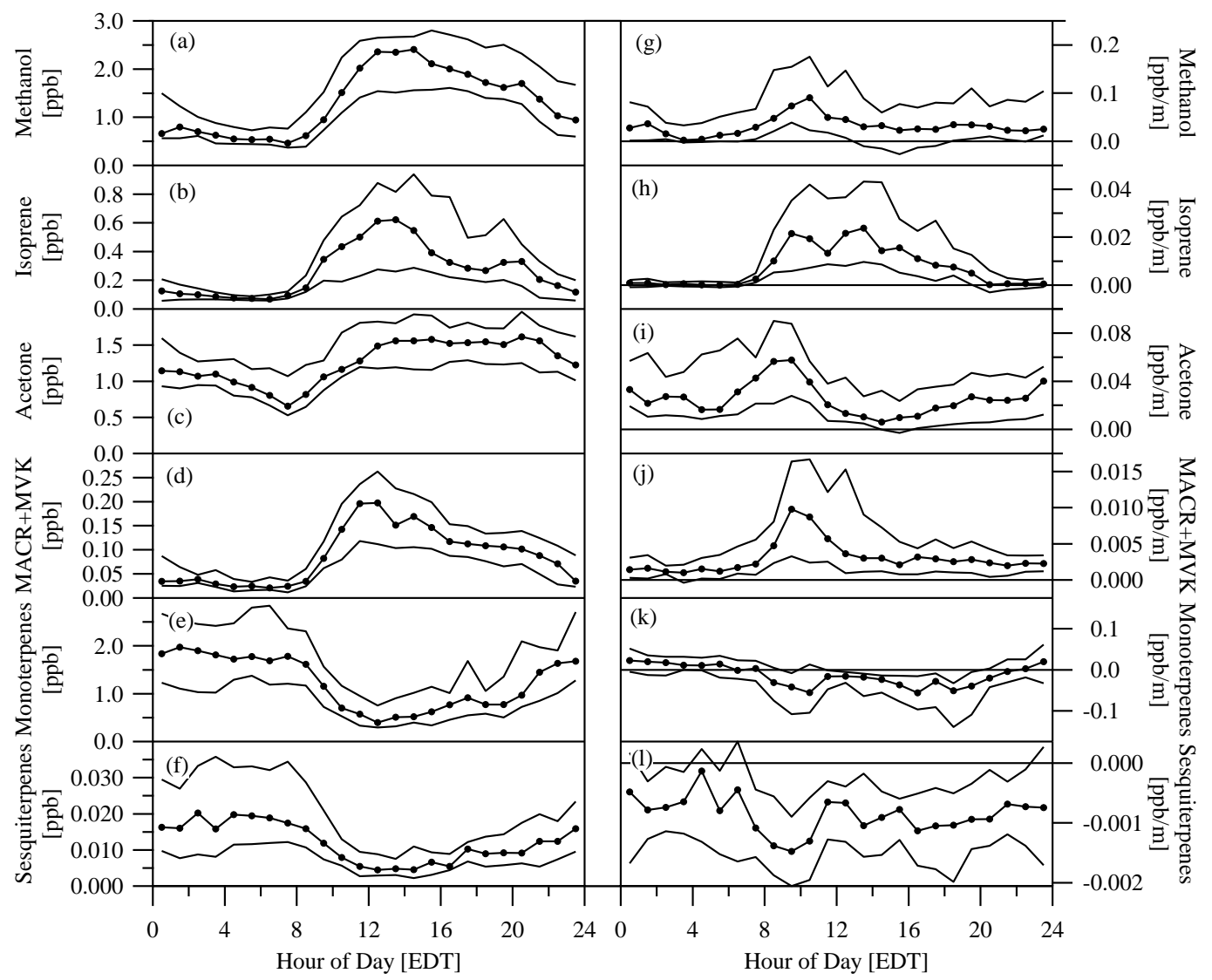

Figure 2. Hourly medians and quartiles of VOC mixing ratios (a-f) and slopes (g-l) over the 22 day measurement period (after filtering for wind direction). Mixing ratios [ppb] are at the $2 \mathrm{~m}$ level and slopes [ppb m${ }^{-1}$ ] are determined as a least-squares fit between 1 and $6 \mathrm{~m}$. Sesquiterpene mixing ratio and slope $(\mathbf{f}, \mathbf{l})$ are not calibrated and are presented as relative units only.

the two forests. Initial tests of the model with the new diffusion scheme at the Borden forest location demonstrated that a transport lifetime of $\tau=4.0 T_{\mathrm{L}}$ gave the best measurement/model comparison, which implies that the change in mixing timescale is due to the change in the diffusion scheme and not the canopy structure.

Makar et al. (1999) modelled an isoprene basal emission rate of $17.5 \mu \mathrm{g} \mathrm{g}^{-1} \mathrm{~h}^{-1}$ and an $\alpha$-pinene basal emission rate of $3.4 \mu \mathrm{g} \mathrm{g}^{-1} \mathrm{~h}^{-1}$. The isoprene basal emission rate was generated to match model results to measurements of isoprene at 30 and $42 \mathrm{~m}$ heights, and the $\alpha$-pinene basal emission was based on a parameterization. Stroud et al. (2005) added sesquiterpenes to the model, represented by $\beta$-caryophyllene. In the Stroud et al. (2005) model, the basal emission rate of sesquiterpenes was set to one-third the monoterpene emission rate. They estimated the dry deposition velocities of $\mathrm{O}_{3}$ as $4 \mathrm{~mm} \mathrm{~s}^{-1}, \mathrm{HNO}_{3}$ as $40 \mathrm{~mm} \mathrm{~s}^{-1}$, $\mathrm{NO}_{2}$ as $1 \mathrm{~mm} \mathrm{~s}^{-1}$, isoprene as $2 \mathrm{~mm} \mathrm{~s}^{-1}$, MACR + MVK as $2 \mathrm{~mm} \mathrm{~s}^{-1}$, and surface emission of monoterpenes as $69 \mu \mathrm{g} \mathrm{m}{ }^{-2} \mathrm{~h}^{-1}$. Fluxes into the surface are calculated in the model as the product of deposition velocity and mixing ration concentration at a $1 \mathrm{~m}$ height. No sesquiterpene surface emissions were included in the Stroud et al. (2005) model. These are the parameters we use for the first model run.

\section{Results}

\subsection{Mixing ratio measurements}

Diurnal mixing ratios in the study time period are shown in Fig. 2a-f. Although sesquiterpenes are not calibrated, the relative measurement provides insight into their behaviour. All of the measured VOCs increase in mixing ratio at sunrise, peak between 14:00 and 16:00 EDT (local time), and decrease into the night, with the exception of monoterpenes and sesquiterpenes. Monoterpenes and sesquiterpenes decrease at sunrise to a minimum near 13:00 EDT, and then increase through the rest of the day and night. Generally speaking, the majority of the VOCs follow the diurnal temperature trend shown in Fig. 1a, while the terpenes follow a diurnal trend similar to relative humidity (Fig. 1b).

The range of the median VOC mixing ratios at $z=4 \mathrm{~m}$ are compared to measurements of two other studies in Table 1. In the Karl et al. (2005) study, various VOCs were 
Table 1. A comparison of understorey minimum and maximum median mixing ratios and peak fluxes. Karl et al. (2005) (K05) and Karl and Guenther (2005) (KG05) were in a sweetgum and pine plantation. Holzinger et al. (2005) (H05) and Schade and Goldstein (2001) (SG01) were in a pine plantation. Karl et al. (2004) (K04) was in a tropical forest.

\begin{tabular}{llrrrrrrr}
\hline \multirow{2}{*}{ VOC } & \multicolumn{2}{c}{ Min-Max MR at 4 m $[\mathrm{ppb}]$} & & \multicolumn{3}{c}{ Peak Fluxes $\left[\mu \mathrm{g} \mathrm{m}^{-2} \mathrm{~h}^{-1}\right]$} \\
\cline { 2 - 3 } \cline { 6 - 8 } & This study & K05 & H05 & & KG05 & K04 & SG01 \\
\hline Methanol & $0.5-2.4$ & $0.5-7.0$ & & & -30 & -70 & 250 \\
Isoprene & $0.1-0.6$ & & & & 30 & -100 & \\
Acetone & $0.7-1.6$ & $1.0-4.0$ & & & & -10 & 50 \\
MACR + MVK & $0.02-0.2$ & $\sim 0-2.5$ & & & & & \\
Monoterpenes & $0.4-1.9$ & & $0.5-2$ & & 50 & & \\
\hline
\end{tabular}

measured beneath a sweetgum and pine plantation using a sampling inlet which was continuously moving between the ground and a height of $24 \mathrm{~m}$. The range of measured values are estimated from the Karl et al. (2005) study (their Fig. 7) for a height of $z=4 \mathrm{~m}$. The mixing ratios of methanol and acetone are nearly a factor of 3 higher during the day in the Karl et al. (2005) study compared to our measurements and the mixing ratios of MACR $+\mathrm{MVK}$ are more than a factor of 12 higher. In the Holzinger et al. (2005) study, monoterpene mixing ratios were measured at 5 heights in a pine plantation. The range of measured values are estimated from the Holzinger et al. (2005) study (their Fig. 2) for a height of $z=4 \mathrm{~m}$. This measured range is similar to the diurnal range of mixing ratio seen in this study at the same height.

For turbulent transport of material, neglecting chemical effects, the change in mixing ratio with height (slope) can be an indication of the direction and relative magnitude of the material flux. The slope of VOC mixing ratio with height is determined between 1 and $6 \mathrm{~m}$ with a linear least-squares fit to each $30 \mathrm{~m}$ profile measurement. The diurnal trend of the slopes is shown for each VOC in Fig. 1g-1. As with the mixing ratios, the slopes follow similar patterns, with the exception of the terpenes. The change in mixing ratio with height at night is generally near-zero, although positive acetone and negative sesquiterpene slopes are seen. The daytime slopes suggest an uptake of non-terpene VOCs and an emission of monoterpenes and sesquiterpenes by the soil and/or forest litter during the day. However, since these are chemically reactive species which may not be conserved with height, further investigation is necessary to demonstrate that these slopes are the result of surface deposition or emissions.

The peak daytime median fluxes from previous studies are compared in Table 1. There have been few studies which have measured VOC fluxes below the canopy and only a small number of VOCs have been measured. Measurements in a pine plantation (Schade and Goldstein, 2001) and a sweetgum and pine plantation (Karl and Guenther, 2005) give varied results, with observations of both emission and uptake of methanol, and emission of acetone, isoprene, and monoterpenes. Although the change in mixing ratio with height (slope) suggests an apparent emission of monoterpenes in the Borden forest measurements, the slope of methanol, acetone, and isoprene suggests a predominantly downward flux. This pattern is similar to the measurements of Karl et al. (2004) beneath a tropical forest, where uptake of methanol, acetone, and isoprene are also seen. The Karl et al. (2004) and Karl and Guenther (2005) fluxes were calculated between 0 and $5 \mathrm{~m}$ (compared to $1-6 \mathrm{~m}$ for this study), while the heights of the Schade and Goldstein (2001) measurements are not specified.

\subsection{Model comparison}

In order to investigate whether or not the measured mixing ratio slopes are due to surface emissions and deposition, the 1-D canopy model was run with and without surface deposition and fluxes. To best match measurements, the basal emission rates were modified to give $21.2 \mu \mathrm{g} \mathrm{g}^{-1} \mathrm{~h}^{-1}$ for isoprene, $2.3 \mu \mathrm{g} \mathrm{g}^{-1} \mathrm{~h}^{-1}$ for monoterpenes, and $0.33 \mu \mathrm{g} \mathrm{g}^{-1} \mathrm{~h}^{-1}$ for sesquiterpenes (although this is only an estimate based on uncalibrated sesquiterpene measurements). This represents an increase of $20 \%$ and a decrease of $11.5 \%$ from the Makar et al. (1999) isoprene and monoterpene basal emission rates, respectively, and a factor of 3.5 decrease from the Stroud et al. (2005) sesquiterpene basal emission rate. In the case of the Stroud et al. (2005) study, these differences are likely due to the different forest environments. The differences between the Makar et al. (1999) study and this one (which takes place in the same location) could be due to the model constraint to below-canopy measurements at a height of $6 \mathrm{~m}$, as opposed to the 30 and $42 \mathrm{~m}$ measurement constraints used by Makar et al. Because turbulent transport within the canopy, chemistry, and light penetration into the canopy can affect the vertical distribution of VOCs, the $20 \%$ increase in isoprene basal emission rate may be due to errors in the vertical distribution of isoprene. However, basal emission rate changes between the studies could also be due to changing forest composition between 1995 and 2009 and to different temperature and moisture histories.

The model was run with two scenarios: a base case with no surface emissions or deposition, and an active surface case which included deposition of isoprene and MACR + MVK, 


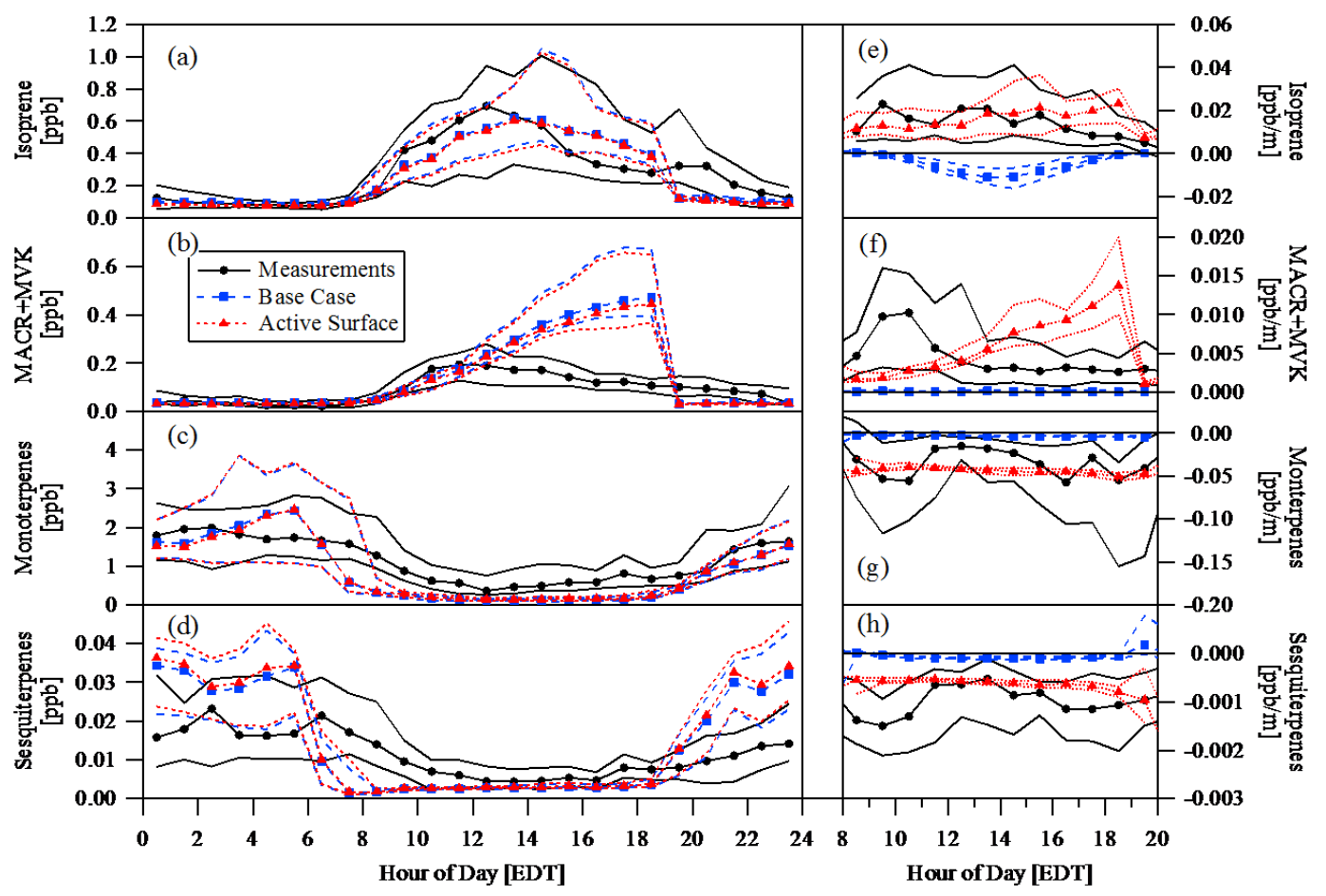

Figure 3. Hourly medians and quartiles of measured and modelled mixing ratios (a-d) and daytime slopes (e-h). Measurements (black circles), the base model case (blue squares), and the active surface case (red triangles) are compared. Sesquiterpene measured mixing ratios and slopes $(\mathbf{d}, \mathbf{h})$ are not calibrated and are presented with units in order to compare to the model output.

and emissions of monoterpenes and sesquiterpenes. Based on initial test runs, daytime surface deposition velocities were modified to $2.7 \mathrm{~mm} \mathrm{~s}^{-1}$ for isoprene and $1.2 \mathrm{~mm} \mathrm{~s}^{-1}$ for MACR + MVK. Surface emission rates were modified to $63 \mu \mathrm{g} \mathrm{m}^{-2} \mathrm{~h}^{-1}$ for monoterpenes and $0.86 \mu \mathrm{g} \mathrm{m}^{-2} \mathrm{~h}^{-1}$ for sesquiterpenes. This represents a $35 \%$ increase for isoprene, a $40 \%$ decrease for MACR + MVK, a $7 \%$ decrease for monoterpenes, and a $19 \%$ decrease for sesquiterpenes from the Stroud et al. (2005) deposition velocities and emission rates at a pine plantation.

The resulting modelled mixing ratios at a height of $6 \mathrm{~m}$ are compared to the measurements in Fig. 3a-d. The active surface has a negligible effect on the mixing ratios compared to the base case scenario. Generally, the model output of isoprene and monoterpene mixing ratios are within the quartiles of measured values. Methacrolein and methyl vinyl ketone are over-predicted by the model in the late afternoon. This over-prediction is discussed further in Sect. 4.2. Both monoterpenes and sesquiterpenes decrease to background levels in the model between 06:00 and 08:00 EDT (sunrise), while the measurements reduce more slowly, between 06:00 and 11:00EDT. Model statistics for the base case are compared in Table 2. The model demonstrates relatively good agreement for isoprene $\left(r^{2}=0.5\right.$ and $65 \%$ of modelled values between 50 and $150 \%$ of the observations),
Table 2. A comparison of mean mixing ratios from observation $\left(\mu_{\mathrm{O}}\right)$ and model output $\left(\mu_{\mathrm{M}}\right)$ for the 22 day period. Coefficient of correlation $\left(r^{2}\right)$, root-mean-square error $\left(E_{\mathrm{rms}}\right)$, and the fraction of modelled $30 \mathrm{~min}$ averages between 50 and $150 \%$ of the observed $30 \mathrm{~min}$ averages are listed.

\begin{tabular}{lccccc}
\hline & $\begin{array}{c}\mu_{\mathrm{O}} \\
\mathrm{ppb}\end{array}$ & $\begin{array}{c}\mu_{\mathrm{M}} \\
\mathrm{ppb}\end{array}$ & $r^{2}$ & $\begin{array}{c}E_{\mathrm{rms}} \\
\mathrm{ppb}\end{array}$ & $\begin{array}{c} \pm 50 \% \\
\%\end{array}$ \\
\hline Isoprene & 0.30 & 0.32 & 0.51 & 0.25 & 64.6 \\
MACR + MVK & 0.16 & 0.10 & 0.26 & 0.19 & 39.6 \\
Monoterpenes & 0.94 & 1.27 & 0.27 & 1.09 & 42.0 \\
Sesquiterpenes & 0.01 & 0.01 & 0.11 & 0.01 & 37.4 \\
\hline
\end{tabular}

moderate agreement for MACR + MVK and monoterpenes $\left(r^{2} \sim 0.3\right)$, and poor agreement for sesquiterpenes $\left(r^{2}=0.1\right)$.

The slopes of mixing ratio with height were calculated from model results between 1 and $6 \mathrm{~m}$ from a linear least-squares fit. The slopes for the daytime hours are compared in Fig. 3e-h. In the base model case, the slopes of isoprene are negative compared to the positive slopes seen in the measurements, and the modelled slopes of MACR + MVK, monoterpenes, and sesquiterpenes are negligible relative to the measurements. Inclusion of isoprene deposition in the model gives slopes similar to the observed values. Deposition of MACR + MVK gives slopes which underestimate 


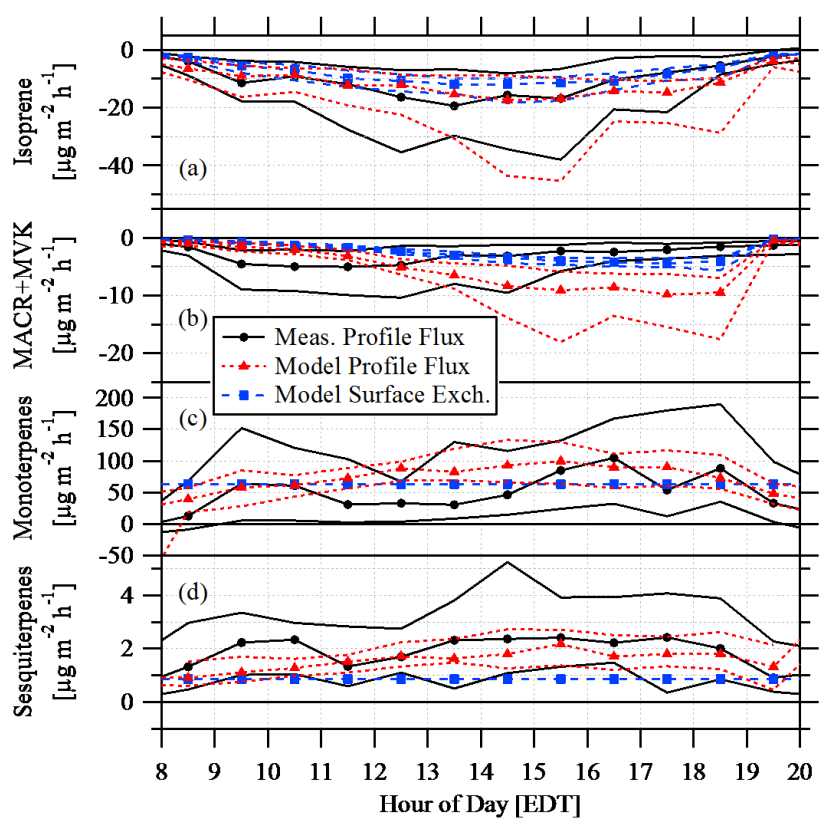

Figure 4. Hourly medians and quartiles of fluxes $\left[\mu \mathrm{g} \mathrm{m}^{-2} \mathrm{~h}^{-1}\right.$ ] as determined from the profile method and compared to the modelled surface exchange fluxes (blue squares). The profile method is used to estimate surface fluxes with both the measurements (black circles) and the model results (red triangles) between 1 and $6 \mathrm{~m}$ heights.

the observed slopes in the morning and overestimate the observed slopes in the afternoon. Emission of monoterpene and sesquiterpenes from the surface by the model produces slopes which are similar to the observed values.

There is good agreement between the measured and modelled slopes for isoprene and MACR + MVK at night between 20:00 and 08:00EDT (not shown). During this time period, the mixing ratios and slopes of isoprene and MACR + MVK are near zero, as shown in Fig. $2 b, d, h$ and $\mathrm{j}$. Because the ground fluxes in the active surface model case are input as deposition velocities for isoprene and MACR + MVK, the near-zero concentrations at night result in low deposition fluxes (from the definition of deposition velocity as the ratio of flux to concentration). For monoterpenes and sesquiterpenes, which are input as surface fluxes in the active surface model case, the modelled slopes are non-zero at night, which is in disagreement with the observed slopes, as shown in Fig. 4k and 1. Due to the difficulty in determining fluxes at night and the disagreement between measured and modelled slopes during this period, the actual behaviour of terpene emissions during the night remains unclear.

\section{Discussion}

\subsection{Canopy-top fluxes}

Based on these model results, the average fluxes from the surface due to deposition of isoprene $\left(2.7 \mathrm{~mm} \mathrm{~s}^{-1}\right)$ and MACR + MVK $\left(1.2 \mathrm{~mm} \mathrm{~s}^{-1}\right)$ and emissions of monoterpenes and sesquiterpenes are calculated for the 22 day period (after filtering for wind direction). These are compared to the average modelled fluxes at the canopy top (upward positive) in Table 3 for the active surface case model run. Due to the uncertainty in the nighttime emissions of terpenes, as discussed in Sect. 3.2, the monoterpene and sesquiterpene surface emissions are presented as a range between zero emissions at night and constant emissions for the full $24 \mathrm{~h}$ period. The average emissions seen here are much larger than those measured by Aaltonen et al. (2011) in a boreal Scots pine forest in southern Finland. Aaltonen et al. measured yearly average emissions of $0.05 \mu \mathrm{g} \mathrm{m}^{-2} \mathrm{~h}^{-1}$ for isoprene, $5 \mu \mathrm{g} \mathrm{m}^{-2} \mathrm{~h}^{-1}$ for monoterpenes, and $0.04 \mu \mathrm{g} \mathrm{m}^{-2} \mathrm{~h}^{-1}$ for sesquiterpenes. These large differences are likely due to differences in the climates, tree compositions and densities, and seasons. For example, in the Aaltonen et al. (2011) study, $\alpha, \beta$-pinene emissions increased by a factor of between 3 and 5 in June and October. Similar seasonal differences could change results at this mixed-forest location for different time periods.

As shown in Table 3, the model suggests that the amount of isoprene that is emitted from the forest to the atmosphere is reduced by approximately $2 \%$ due to surface uptake. Although this is a relatively small fraction of the total, on a regional scale this could have a significant effect on the total isoprene released from forests. With the inclusion of MACR + MVK deposition, there is negligible release of MACR + MVK to the atmosphere from the canopy over the period of the study and any MACR + MVK that is created as a by-product of chemical reactions is, on average, absorbed at the forest surface. This is consistent with the small canopytop fluxes for MACR + MVK seen in other studies (Karl et al., 2004; Spirig et al., 2005).

According to model results, the emission of monoterpenes from the surface represents a significant amount (15 to $27 \%$ ) of what is released from the canopy-top to the atmosphere. This is a much larger fraction than the $10 \%$ which was modelled by Stroud et al. (2005) for a pine plantation using the same canopy model. This is an important result for the interpretation of measured canopy-top emissions relating to basal tree emission rates. Although a large fraction of monoterpene emissions may relate to leaf respiration, a significant amount may also be due to leaf litter or other unknown surface emissions. Hence, basal tree emission rates based on canopy-top emission measurements may be overestimated.

Faiola et al. (2014) measured VOC emissions from soil and leaf litter samples collected from a pine and larch forest in Idaho. They measured peak monoterpene emission rates from the samples of $258 \mu \mathrm{g} \mathrm{m}^{-2} \mathrm{~h}^{-1}$. Comparing these 
Table 3. The average modelled fluxes (positive upward) from the surface $\left(F_{\mathrm{S}}\right)$ and at the canopy top $\left(F_{\mathrm{C}}\right)$ in units of $\mu \mathrm{g} \mathrm{m} \mathrm{m}^{-2} \mathrm{~h}^{-1}$. A range is given for terpenes with emissions from 08:00-20:00 EDT only (no nighttime emissions) and emissions from 00:00-24:00 EDT (full day).

\begin{tabular}{llllll}
\hline & \multicolumn{1}{c}{$F_{\mathrm{S}}$} & $F_{\mathrm{C}}$ & \multicolumn{1}{c}{$F_{\mathrm{S}} / F_{\mathrm{C}}$} \\
\hline Isoprene & \multicolumn{2}{c}{-5.2} & 243.5 & $-2.1 \%$ \\
MACR + MVK & \multicolumn{2}{c}{-1.5} & -0.01 & & \\
& $08: 00-20: 00$ & $00: 00-24: 00$ & & $08: 00-20: 00$ & $00: 00-24: 00$ \\
Monoterpenes & 31.4 & 62.9 & 234.7 & $15.4 \%$ & $26.8 \%$ \\
Sesquiterpenes & 0.4 & 0.9 & 18.7 & $2.3 \%$ & $4.7 \%$ \\
\hline
\end{tabular}

Table 4. Percentage change in average mixing ratio and slope for a 2 day model run with modified: input NO; transport lifetime $(\tau)$, input $\mathrm{O}_{3}$; and input solar flux. Changes are relative to the "active surface" model run.

\begin{tabular}{lrrrrrrrr}
\hline Mixing ratios & $1.5 \mathrm{NO}$ & $0.5 \mathrm{NO}$ & $1.5 \tau$ & $0.5 \tau$ & $1.5 \mathrm{O}_{3}$ & $0.5 \mathrm{O}_{3}$ & $1.5 \mathrm{I}$ & $0.5 \mathrm{I}$ \\
\hline Isoprene & 13.7 & -16.8 & -0.5 & 7.8 & 5.9 & -9.5 & -17.1 & 53.0 \\
MACR + MVK & 7.9 & -14.0 & -0.3 & 0.3 & 5.4 & -11.3 & -20.8 & 12.9 \\
Monoterpenes & 8.3 & -12.9 & -0.7 & 10.0 & -11.8 & 14.5 & -3.3 & 6.3 \\
Sesquiterpenes & 25.5 & -30.1 & -0.7 & 8.6 & -18.2 & 40.1 & -1.0 & 1.6 \\
\hline Slopes & $1.5 \mathrm{NO}$ & $0.5 \mathrm{NO}$ & $1.5 \tau$ & $0.5 \tau$ & $1.5 \mathrm{O}_{3}$ & $0.5 \mathrm{O}_{3}$ & $1.5 I$ & $0.5 I$ \\
\hline Isoprene & 24.9 & -27.0 & -3.0 & 46.2 & 13.9 & -19.3 & -31.7 & 107.5 \\
MACR + MVK & 12.9 & -22.4 & -2.3 & 28.8 & 7.8 & -16.4 & -29.5 & 22.5 \\
Monoterpenes & -2.3 & 2.5 & -1.6 & 21.0 & 1.3 & -2.7 & 2.7 & -6.0 \\
Sesquiterpenes & 2.1 & -2.9 & -1.9 & 29.6 & -12.5 & 16.8 & -1.2 & 0.7 \\
\hline
\end{tabular}

measurements to model results, they conclude that surface monoterpene emissions could account for between 12 and $136 \%$ of the canopy emissions in the spring and fall.

Although sesquiterpene measurements in this study were uncalibrated, the model output provides some insight into the relative surface flux of sesquiterpenes. According to the model estimates, approximately 2 to $5 \%$ of sesquiterpenes emitted at the canopy top are due to surface emissions. Although we are not able to confirm the basal tree and surface emission rates used in the model, sesquiterpene emissions from canopies are typically more than an order of magnitude lower than they are for primary VOCs such as isoprene, suggesting that the emissions of sesquiterpenes from the subcanopy surface is not significant.

\subsection{Model sensitivity and uncertainty}

To estimate the error in the model due to the estimation of model input NO from nearby measurements, two 2 day model runs were done with modified NO levels. The active surface case was used with a $50 \%$ increase in NO levels and a $50 \%$ reduction in NO. The resulting change in the average mixing ratio and daytime slope of isoprene, MACR + MVK, monoterpenes, and sesquiterpenes are listed in Table 4. Changes in average mixing ratios and slopes for these compounds are generally less than or near $\pm 50 \%$.

As discussed in Sect. 2.2, the Egbert NO measurements used as a proxy for the Borden measurements correlate well $\left(r^{2}=0.68\right)$ with an average of $0.26 \mathrm{ppb}$ at Egbert and $0.27 \mathrm{ppb}$ at Borden. However, there is a high root-meansquare error $\left(E_{\mathrm{rms}}=0.66 \mathrm{ppb}\right)$ over the same period, primarily due to high NO values seen at only one site during nonaligned wind directions. In the model sensitivity runs, the average VOC mixing ratio and slope changes due to modified NO levels are consistently smaller than the $50 \%$ increase and decrease in NO. Hence, it would be expected that over the 22 days of the study, the average error due to the use of proxy NO levels should be near the $6 \%$ average difference in NO between Egbert and Borden; however hourly errors may be much higher, as suggested by the relatively high root-meansquare error.

The model significantly over-predicts MACR + MVK in the afternoon (Fig. 3b). The measured slope of MACR + MVK is highest in the morning hours (Fig. 3f) and is then relatively constant in the afternoon. The modelled slope of MACR + MVK increases throughout the day. These results suggest that the model is either producing MACR + MVK too rapidly or it is not being removed quickly enough. A model sensitivity run with a $50 \%$ increase in the MACR + MVK deposition rate at the surface has little effect on the mixing ratio ( $<1 \%$ average difference) and an average $38 \%$ increase in the slope. Hence, it is unlikely that the modelled surface deposition is too low. The model does not include deposition to leaf stomata within the canopy. Karl et al. (2010) have demonstrated total integrated canopy deposition rates as high as $24 \mathrm{~mm} \mathrm{~s}^{-1}$ for MACR + MVK. 
Methacrolein has also been shown to form secondary organic aerosols from photo-oxidation (Zhang et al., 2012) a process which is not included in the model. Production of aerosols is supported by a concurrent study at the same location (Gordon et al., 2011) which found that the forest is a net source of aerosols. Both the lack of canopy deposition and aerosol production may account for the modelled overprediction of MACR + MVK and should be included in future model versions.

Further sensitivity tests were run for the same 2 day period with a modified transport lifetime ( $\tau$ in Eqs. 2 and 3), $\mathrm{O}_{3}$ levels, and solar flux ( $I$, photons $\left.\mathrm{m}^{-2} \mathrm{~s}^{-1} \mathrm{~nm}^{-1}\right)$. The modifications result in average isoprene mixing ratio changes between -17 and $53 \%$ and average isoprene slope changes between -27 and $108 \%$. The isoprene slope is very sensitive to light conditions, as demonstrated by the reduced solar flux run $(0.5 I)$, which results in a $108 \%$ increase in average slope. Monoterpenes are generally much less sensitive to the modifications, with average mixing ratio changes between -12 and $15 \%$ and average slope changes between -6 and $21 \%$. Although it is difficult to quantify the uncertainty in input variables such as $\tau, \mathrm{O}_{3}$, and $I$, these tests demonstrate that the model error should be on the same scale as these uncertainties. For example, the $20 \%$ increase in isoprene basal emissions rates relative to the Makar et al. (1999) study could be due to an uncertainty of the same scale introduced by the below-canopy $(6 \mathrm{~m})$ model constraint. A change in light conditions in the sub-canopy will change the amount of isoprene and necessitate a change in the basal emission rate to compensate. Hence, the error in the isoprene slope (and hence the derived deposition) may be as much as $40 \%$, while error in monoterpene emissions are likely less.

\subsection{A comparison to profile method fluxes}

It is generally considered incorrect to derive flux-profile relationships below the canopy, as the assumption of uniform mixing is violated by canopy structures (e.g. Garratt, 1994). However, a recent study (Vickers and Thomas, 2014) demonstrates accurate measurements of heat flux beneath a canopy using the flux-profile relationship. To investigate the utility of this approach here, surface fluxes are derived from the mixing ratio measurements between the heights of 1 and $6 \mathrm{~m}$. The derivation of the fluxes is outlined in the supplementary material. Figure 4 compares the daytime profile fluxes (derived from both the measurements and the model output between heights of 1 and $6 \mathrm{~m}$ ) and the surface exchange (deposition and ground emissions) specified in the active surface model run. The fluxes derived from the profile method systematically overestimate the specified surface exchange fluxes. However, the specified surface exchange fluxes are generally within the upper and lower quartiles of the profile method fluxes. Although the profiles may not be quantitatively accurate, they are directionally consistent. This suggests that the positive slopes of methanol and acetone (Fig. 2) demonstrate a deposition of these VOCs to the surface, in contrast to measured emissions from litter samples (Warneke et al., 1999).

\section{Conclusions}

Direct measurements of VOC mixing ratios between 1 and $6 \mathrm{~m}$ demonstrate a trend of increasing methanol, isoprene, acetone, and MACR + MVK during the day, and increasing monoterpenes and sesquiterpenes during the night for this forest location. Mixing ratios of methanol, acetone, and monoterpenes compare well to other near-surface measurements made at pine plantations and plantations with both sweetgum and pine.

The change in mixing ratio with height suggests a downward flux of methanol, isoprene, acetone, and MACR + MVK during the day, and an upward flux of monoterpenes and sesquiterpenes during the day. Slopes through the night are generally near zero. There is a large amount of variation in observed fluxes of VOCs near the surface in previous studies; however directional consistency is seen between measurements at the Borden forest and the deposition of methanol, isoprene, and acetone in a tropical forest (Karl et al., 2004). There is also directional consistency with the emission of monoterpenes from a Scots pine forest (Aaltonen et al., 2011).

A 1-D canopy model was used to determine if the change in VOC mixing ratios with height was due to deposition and emissions of VOCs to the sub-canopy surface. Model results suggest a deposition of $2.7 \mathrm{~mm} \mathrm{~s}^{-1}$ for isoprene which results in average downward (negative) surface flux of $4.9 \mu \mathrm{g} \mathrm{m}^{-2} \mathrm{~h}^{-1}$ for the duration of the study. This represents $2 \%$ of the magnitude of the canopy-top emissions of isoprene to the atmosphere. Model results suggest a deposition of $1.2 \mathrm{~mm} \mathrm{~s}^{-1}$ for MACR + MVK which results in an average downward (negative) surface flux of $1.4 \mu \mathrm{g} \mathrm{m}^{-2} \mathrm{~h}^{-1}$. This compensates for the formation of MACR + MVK in the canopy, resulting in negligible emissions of MACR + MVK from the canopy top to the atmosphere. Results suggest a surface emission of $63 \mu \mathrm{g} \mathrm{m}^{-2} \mathrm{~h}^{-1}$ for monoterpenes, which comprises 15 to $27 \%$ of the total emissions from the canopytop to the atmosphere. This represents a significant fraction of the emitted monoterpenes, suggesting that forest surface emissions at this location are comparable in scale to the emissions from tree foliage and should be taken into account in canopy modelling. These results are similar to the results of Faiola et al. (2014), who suggest that surface monoterpene emissions could account for between 12 and $136 \%$ of the canopy emissions in the spring and fall. Results were less conclusive for sesquiterpenes, owing in part to the lack of a calibration standard. However, it appears that the emissions of sesquiterpenes from the sub-canopy surface are generally not significant. 
This study represents explorative research into VOC deposition and emissions from the sub-canopy surface of a mixedforest location. Further study is necessary in order to study the variation of surface emissions seasonally and the behaviour of terpene emissions during the night, and to quantify VOC concentrations for the entire forest height, which would allow for the verification of model results for the full height of the canopy. The VOC exchange to and from soil and litter at the surface is also poorly constrained (e.g. Stacheter et al., 2013; Faiola et al., 2014; Leff and Fierer, 2008) and further investigation is required to identify the sources of emission and deposition.

\section{The Supplement related to this article is available online at doi:10.5194/acp-14-9087-2014-supplement.}

Acknowledgements. This work was supported by the Natural Science and Engineering Research Council of Canada and was funded by the Science and Technology Branch, Environment Canada. The authors thank the Canadian Forces Base Borden for hosting the flux tower site.

Edited by: J. Williams

\section{References}

Aaltonen, H., Pumpanen, J., Pihlatie, M., Hakola, H., Hellen, H., Kulmala, L., Vesala, T., and Back, J.: Boreal pine forest floor biogenic volatile organic compound emissions peak in early summer and autumn, Agr. Forest Meteorol., 151, 682-691, 2011.

Barr, A. G., Griffis, T. J., Black, T. A., Lee, X., Staebler, R. M., Fuentes, J. D., Chen, Z., and Morgenstern, K.: Comparing the carbon budgets of boreal and temperate deciduous forest stands, Can. J. Forest Res., 32, 813-822, 2002.

Brown, S., Warland, J., Santos, E., Wagner-Riddle, C., Staebler, R., and Wilton, M.: Estimating a Lagrangian length scale using measurements of $\mathrm{CO}_{2}$ in a plant canopy, Bound.-Lay. Meteorol., 147, 83-102, doi:10.1007/s10546-012-9778-6, 2013.

Calogirou, A., Larsen, B., and Kotzias, D.: Gas-phase terpene oxidation products: a review, Atmos. Environ., 33, 1423-1439, 1999

Chang, K.-H.: Modelling carbon dynamics in a agriculture and forest exosystems using the process-based models DayCENT and CN-CLASS, Ph.D. Thesis, University of Guelph, Guelph, Canada, 2011.

Côté, J., Gravel, S., Méthot, A., Patoine, A., Roch, M., and Staniforth, A.: The operational CMC-MRB Global Environmental Multiscale (GEM) model: Part I - Design considerations and formulation, Mon. Weather Rev., 126, 1373-1395, 1998.

de Gouw, J. A., Howard, C. J., Custer, T. G., and Fall, R.: Emissions of volatile organic compounds from cut grass and clover are enhanced during the drying process, Geophys. Res. Lett., 26, 811-814, 1999
Faiola, C. L., VanderSchelden, G. S., Wen, M., Elloy, F. C., Cobos, D. R., Watts, R. J., Jobson, B. T., and VanReken, T. M.: SOA Formation Potential of Emissions from Soil and Leaf Litter, Environmental Sci. Technol., 48, 938-946, 2014.

Folkers, A., Hve, K., Ammann, C., Dindorf, T., Kesselmeier, J., Kleist, E., Kuhn, U., Uerlings, R., and Wildt, J.: Methanol emissions from deciduous tree species: dependence on temperature and light intensity, Plant Biol., 10, 65-75, 2008.

Fruekilde, P., Hjorth, J. N. R., Kotzias, D., and Larsen, B.: Ozonolysis at vegetation surfaces: A source of acetone, 4-oxopentanal, 6-methyl-5-hepten-2-one and geranyl acetone, Atmos. Environ., 32, 1893-1902, 1998.

Garratt, J. R.: The Atmospheric Boundary Layer, Cambridge University Press, Cambridge, 1994.

Gordon, M., Staebler, R. M., Liggio, J., Vlasenko, A., Li, S.-M., and Hayden, K.: Aerosol flux measurements above a mixed forest at Borden, Ontario, Atmos. Chem. Phys., 11, 6773-6786, doi:10.5194/acp-11-6773-2011, 2011.

Guenther, A., Hewitt, C. N., Erickson, D., and Fall, R.: A global model of natural volatile organic compound emissions, J. Geophys. Res., 100, 8873-8892, 1995.

Guenther, A. B., Monson, R. K., and Fall, R.: Isoprene and monoterpene emission rate variability: Observations with Eucalytus and emission rate algorithm development, J. Geophys. Res., 96, 10799-10808, 1991.

Holzinger, R., Lee, A., Paw, K. T., and Goldstein, U. A. H.: Observations of oxidation products above a forest imply biogenic emissions of very reactive compounds, Atmos. Chem. Phys., 5, 67-75, doi:10.5194/acp-5-67-2005, 2005.

Karl, T. and Guenther, A.: Biosphere-atmosphere exchange investigated using PTR-MS, in: Proc. of 2nd international Conference on Proton Transfer Reaction Mass Spectrometry and Its Applications, 29 January-3 February 2005, edited by: Hansel, A. and Mark, T., Obergurgl, Austria, 2005.

Karl, T., Potosnak, M., Guenther, A., Clark, D., Walker, J., Herrick, J. D., and Geron, C.: Exchange processes of volatile organic compounds above a tropical rain forest: Implications for modelling tropospheric chemistry above dense vegetation. J. Geophys. Res., 109, D18306, doi:10.1029/2004JD004738, 2004.

Karl, T., Harley, P., Guenther, A., Rasmussen, R., Baker, B., Jardine, K., and Nemitz, E.: The bi-directional exchange of oxygenated VOCs between a loblolly pine (Pinus taeda) plantation and the atmosphere, Atmos. Chem. Phys., 5, 3015-3031, doi:10.5194/acp-5-3015-2005, 2005.

Karl, T., Harley, P., Emmons, L., Thornton, B., Guenther, A., Basu, C., Turnipseed, A., and Jardine, K.: Efficient Atmospheric Cleansing of Oxidized Organic Trace Gases by Vegetation, Science, 330, 816-819, 2010.

Kim, S., Karl, T., Helmig, D., Daly, R., Rasmussen, R., and Guenther, A.: Measurement of atmospheric sesquiterpenes by proton transfer reaction-mass spectrometry (PTR-MS), Atmos. Meas. Tech., 2, 99-112, doi:10.5194/amt-2-99-2009, 2009.

Kirstine, W., Galbally, I., Ye, Y. R., and Hooper, M.: Emissions of volatile organic compounds (primarily oxygenated species) from pasture, J. Geophys. Res., 103, 10605-10619, 1998.

Kreuzwieser, J., Kühnemann, F., Martis, A., Rennenberg, H., and Urbau, W.: Diurnal pattern of acetaldehyde emission by flooded poplar trees, Plant Physiol., 108, 79-86, 2000. 
Lappalainen, H. K., Sevanto, S., Bäck, J., Ruuskanen, T. M., Kolari, P., Taipale, R., Rinne, J., Kulmala, M., and Hari, P.: Daytime concentrations of biogenic volatile organic compounds in a boreal forest canopy and their relation to environmental and biological factors, Atmos. Chem. Phys., 9, 5447-5459, doi:10.5194/acp-9-5447-2009, 2009.

Lee, X. H., Fuentes, J. D., Staebler, R. M., and Neumann, H. H.: Long-term observation of the atmospheric exchange of $\mathrm{CO}_{2}$ with a temperate deciduous forest in southern Ontario, Canada, J. Geophys. Res.-Atmos., 104, 15975-15984, 1999.

Leff, J. W. and Fierer, N.: Volatile organic compound (VOC) emissions from soil and litter samples, Soil Biol. Biochem., 40, 16291636, 2008.

Makar, P. A., Fuentes, J. D., Wang, D., Staebler, R. M., and Wiebe, H. A.: Chemical processing of biogenic hydrocarbons within and above a temperate deciduous forest, J. Geophys. Res., 104, 35813606, 1999.

Mäkelä, A., Hari, P., Berninger, F., Hänninen, H., and Nikinmaa, E.: Acclimation of photosynthetic capacity in Scots pine to the annual cycle temperature, Tree Physiol., 24, 369-378, 2004.

Oquist, G. and Huner, N.: Photosynthesis of overwintering evergreen plants, Annu. Rev. Plant Biol., 54, 329-355, 2003.

Raupach, M. R.: Applying Lagrangian fluid mechanics to infer scalar source distributions from concentration profiles in plant canopies, Agr. Forest Meteorol., 47, 85-108, 1989.

Santos, E., Wagner-Riddle, C., Lee, X., Warland, J., Brown, S., Staebler, R., Bartlett, P., and Kim, K.: Use of the isotope flux ratio approach to investigate the $\mathrm{C}^{18} \mathrm{O}^{16} \mathrm{O}$ and ${ }^{13} \mathrm{CO}_{2}$ exchange near the floor of a temperate deciduous forest, Biogeosciences, 9, 2385-2399, doi:10.5194/bg-9-2385-2012, 2012.

Schade, G. W. and Goldstein, A. H.: Fluxes of oxygenated volatile organic compounds from a ponderosa pine plantation, J. Geophys. Res., 106, 3111-3123, 2001.

Schade, G. W., Hofmann, R. M., and Crutzen, P. J.: CO emissions from degrading plant matter, I: Measurements, Tellus B, 51, 889908, 1999

Schade, G. W., Solomon, S. J., Dellwik, E., Pilegaard, K., and Ladstatter-Weissenmayer, A.: Methanol and other VOC fluxes from a Danish beech forest during late springtime, Biogeochemistry, 106, 337-355, doi:10.1007/s10533-010-9515-5, 2010.

Spirig, C., Neftel, A., Ammann, C., Dommen, J., Grabmer, W., Thielmann, A., Schaub, A., Beauchamp, J., Wisthaler, A., and Hansel, A.: Eddy covariance flux measurements of biogenic VOCs during ECHO 2003 using proton transfer reaction mass spectrometry, Atmos. Chem. Phys., 5, 465-481, doi:10.5194/acp-5-465-2005, 2005.
Stacheter A., Noll, M., Lee, C. K., Selzer, M., Glowik, B., Ebertsch, L., Mertel, R., Schulz, D., Lampert, N., Drake, H., and Kolb, S.: Methanol oxidation by temperate soils and environmental determinants of associated methylotrophs, International Society for Microbial Ecology, ISME J., 7, 1051-1064, doi:10.1038/ismej.2012.167, 2013.

Staebler, R. M., Fuentes, J. D., Lee, X. H., Puckett, K. J., Neumann, H. H., Deary, M. J., and Arnold, J. A.: Long term flux measurements at the Borden forest, CMOS Bull. SCMO, 28, 9-16, 2000.

Stroud, C., Makar, P., Karl, T., Guenther, A., Geron, C., Turpinseed, A., Nemitz, E., Baker, B., Potosnak, M., and Fuentes, J.: Role of canopy-scale photochemistry in modifying biogenicatmosphere exchange of reactive terpene species: Results from the CELTIC field study, J. Geophys. Res., 110, D17303, doi:10.1029/2005JD005775, 2005.

Teklemariam, T., Staebler, R., and Barr, A. G.: Eight years of carbon dioxide exchange above a mixed forest at Borden, Ontario, Agr. Forest Meteorol., 149, 2040-2053, 2009.

Tingey, D. T., Manning, M., Grothaus, L. C., and Burns, W. F.: Influence of Light and Temperature on Monoterpene Emission Rates from Slash Pine, Plant Physiol., 65, 797-801, 1980.

Tunved, P., Hansson, H.-C., Kerminen, V.-M., Ström, J., Dal Maso, M., Lihavainen, H., Viisanen, Y., Aaalto, P. P., Komppula, M., and Kulmala, M.: High natural aerosol loading over boreal forests, Science, 312, 261-263, 2006.

Vickers, D. and Thomas, C.: Observations of the scale-dependent turbulence and evaluation of the flux-gradient relationship for sensible heat for a closed Douglas-Fir canopy in very weak wind conditions, Atmos. Chem. Phys. Discuss., 14, 11929-11960, doi:10.5194/acpd-14-11929-2014, 2014.

Warneke, C., Karl, T., Judmaier, H., Hansel, A., Jordan, A., Lindinger, W., and Crutzen, P. J.: Acetone, methanol, and other partially oxidized volatile organic emissions from dead plant matter by abiological processes: Significance for atmospheric $\mathrm{HO}_{\mathrm{x}}$ chemistry, Global Biogeochem. Cy., 13, 9-17, 1999.

Wildt, J., Kobel, K., Schuh-Thomas, G., and Heiden, A. C.: Emissions of Oxygenated Volatile Organic Compounds from Plants Part II: Emissions of Saturated Aldehydes, J. Atmos. Chem., 45, 173-196, 2003.

Zhang, H., Lin, Y.-H., Zhang, Z., Zhang, X., Shaw, S. L., Knipping, E. M., Weber, R. J., Gold, A., Kamens, R. M., and Surratt, J. D.: Secondary organic aerosol formation from methacrolein photooxidation: roles of $\mathrm{NO}_{\mathrm{x}}$ level, relative humidity and aerosol acidity, Environ. Chem., 9, 247-262, 2012. 